\title{
Practitioners praise shadeless composite
}

Some of Europe's top aesthetic practitioners have praised Omnichroma, described as the world's first shadeless composite.

Tokuyama, one of the world's biggest and most innovative dental manufacturers, has eliminated the cost and inconvenience of shade taking with the introduction of its shadeless Omnichroma.

It combines patented 'structural colour' pearl technology with its advanced resin expertise so that just one shadeless Omnichroma and Omnichroma Blocker is all that is needed to replace all 16 Vita shades of any other composite system.

\section{Get right to the root of dental pain}

Root canal treatment is a complex and highly involved procedure, which is why, EndoCare - the specialist practice - says it ensures that with every case it receives, it does its best to offer pain-free treatment.

Using modern techniques, root canal treatment need only be as uncomfortable as receiving a filling, which is why EndoCare is happy to receive referrals of any patients struggling with dental phobias or whose cases are more complex.

Together, its team of endo-experts will provide them with the treatment they require and ensure they are comfortable throughout.

Once done, the practice will return the patient to your care with full details of the treatment they have received and any relevant aftercare.

For more information, call EndoCare on 02072240999 or visit www.endocare.co.uk.

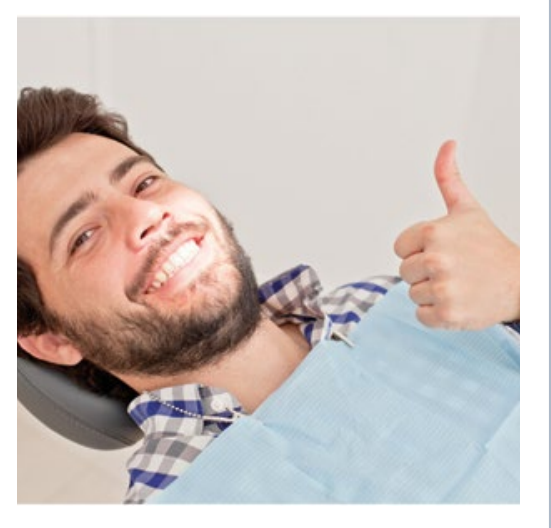

Comments made by aesthetic practitioners include -

- 'First I was sceptical, if the colour matching would fit, but easy application, convincing polishing results and surprisingly good colour matching convinced me, said Dr Markus Lenders from Germany

- 'Omnichroma is an essential composite for any restorative dentist as its colour matching after curing in circumferential enamel cavities is truly unique,' said Dr Thomas Taha from the UK

- 'One colour for all fillings? Sounds completely unbelievable - but actually

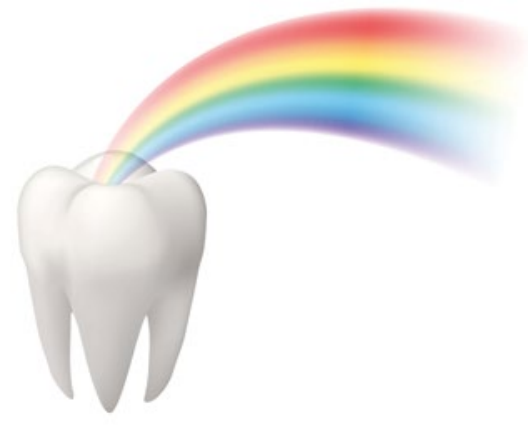

works!' said Professor Dr Claus-Peter Ernst from Germany.

More information about the complete Tokuyama range, including Omnichroma is available by calling 01274885544 or visiting www.trycare.co.uk/omnichroma.

\section{The must-have universal post system}

When a significant amount of coronal tooth structure has been lost following endodontic treatment, a quality post is essential for providing retention for the core restorative material.

For a complete universal endodontic post system suitable for any clinical situation, try the ParaPost $\mathrm{X}$ range from COLTENE; a state-of-the-art post system for all direct post and core build-ups and casting techniques.

All posts within the range have a raised diamond shape retention pattern, making them extremely resistant to oblique forces, and offer high resistance to rotation and tensile retention.

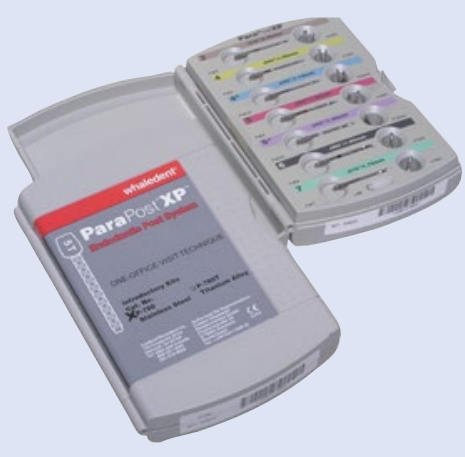

Add the non-end cutting, depthcalibrated drills that provide precise canal preparation, and you have a system that is truly first class.

To find out more, visit www.coltene.com email info.uk@coltene.com or call 01444235486.

\section{A dentolegal firm you can trust}

Hailed as the lawyers for dentists, Goodman Grant is one of the UK's leading law firms.

With almost 100 years combined experience specialising in providing bespoke legal services to the dental profession, Goodman Grant has the expertise and knowledge to assist you.

Be confident that you can rely on the expert team at Goodman Grant, as they treat every case with care, sensitivity and focus to ensure the very best outcome.

Whether you are thinking of buying or selling a practice, settling a dispute, planning partnership agreements, or looking to incorporate your practice, consider Goodman Grant. The firm says its team genuinely cares about clients, working to build relationships with them and paying utmost attention to the details - no matter how big or small the case presented.

With offices in Liverpool, Leeds and London, Goodman Grant makes dentolegal support and advice completely accessible to you, so you can be sure that the team will travel to meet you whenever, or wherever you require.

More information is available by visiting www.goodmangrant.co.uk or contacting your nearest office:

- London: 02031143133

- Leeds: 01138343705

- Liverpool: 01517070090. 